\title{
Annual distribution of allergenic fungal spores in atmospheric particulate matter in the Eastern Mediterranean; a comparative study between ergosterol and quantitative PCR analysis
}

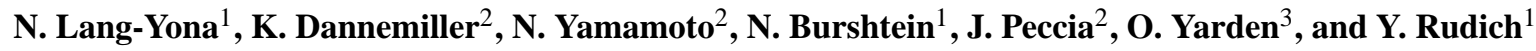 \\ ${ }^{1}$ Department of Environmental Sciences, Weizmann Institute of Science, Rehovot, 76100, Israel \\ ${ }^{2}$ Department of Chemical and Environmental Engineering, Yale University, Mason Laboratory, 9 Hillhouse Avenue, \\ New Haven, CT, 06520-8286, USA \\ ${ }^{3}$ Department of Plant Pathology and Microbiology, The R.H. Smith Faculty of Agriculture, Food and Environment, \\ The Hebrew University of Jerusalem, Rehovot 76100, Israel
}

Correspondence to: Y. Rudich (yinon.rudich@weizmann.ac.il)

Received: 12 September 2011 - Published in Atmos. Chem. Phys. Discuss.: 26 October 2011

Revised: 28 February 2012 - Accepted: 29 February 2012 - Published: 13 March 2012

\begin{abstract}
Airborne fungal spores are an important fraction of atmospheric particulate matter and are major causative agents of allergenic and infectious diseases. Predicting the variability and species of allergy-causing fungal spores requires detailed and reliable methods for identification and quantification. There are diverse methods for their detection in the atmosphere and in the indoor environments; yet, it is important to optimize suitable methods for characterization of fungal spores in atmospheric samples. In this study we sampled and characterized total and specific airborne fungal spores from $\mathrm{PM}_{10}$ samples collected in Rehovot, Israel over an entire year. The total fungal spore concentrations vary throughout the year although the species variability was nearly the same. Seasonal equivalent spore concentrations analyzed by real-time quantitative-PCR-based methods were fall $>$ winter $>$ spring $>$ summer. Reported concentrations based on ergosterol analysis for the same samples were and fall $>$ spring $>$ winter $>$ summer. Correlation between the two analytical methods was found only for the spring season. These poor associations may be due to the per-spore ergosterol variations that arise from both varying production rates, as well as molecular degradation of ergosterol. While conversion of genome copies to spore concentration is not yet straightforward, the potential for improving this conversion and the ability of qPCR to identify groups of fungi or specific species makes this method preferable for environmental spore quantification. Identifying tools for establishing the re-
\end{abstract}

lation between the presence of species and the actual ability to induce allergies is still needed in order to predict the effect on human health.

\section{Introduction}

Fungi are ubiquitous eukaryotic organisms that produce spores with the capability of long-range dispersal throughout the lower troposphere (Breitenbach et al., 2002). Understanding the diversity along with the spatial and temporal distribution of airborne fungal spores is of increasing importance because fungal spores and other propagules can potentially act as sources of plant diseases (Madelin, 1994), human allergens (Breitenbach et al., 2002; Kurup et al., 2000), animal and human infectious agents (Enoch et al., 2006), and produce mycotoxins along with other deleterious secondary metabolites (Garvey and Keller, 2010). The characteristics of an airborne fungal population may be related to different environmental factors, such as seasonality, location, meteorological parameters, relative humidity, and temperature (Burshtein et al., 2011; Fröhlich-Nowoisky et al., 2009; Oliveira et al., 2005). For example, elevated $\mathrm{CO}_{2}$ concentrations (Kilronomos et al., 1997) or increased temperatures (Gange et al., 2007) have been shown to positively correlate with increases in fungal biomass. Some of these changes have been

Published by Copernicus Publications on behalf of the European Geosciences Union. 
associated with global climate change and may impact human health and economics.

Several methods are commonly used to quantify the distribution of airborne fungal spores. Direct quantification can be performed either by conventional microbiological methods (e.g. spore counting or determining the number of colony forming units, CFUs) (Li et al., 2010; Takahashi, 1997), or by nucleic acid-based analyses (e.g. quantitativePolymerase Chain Reaction (q-PCR) of extracted DNA) (Fröhlich-Nowoisky et al., 2009; Hospodsky et al., 2010; Yamamoto et al., 2011). Indirect methods of quantification utilize analytical chemistry for assessing the presence of fungal-specific biomarkers (Bjurman, 1994; Burshtein et al., 2011; Lau et al., 2006; Mille-Lindblom et al., 2004; Miller et al., 1997; Robine et al., 2005), and include the analysis of ergosterol, a membrane sterol, found almost exclusively in fungi (Axelsson et al., 1995; Gessner and Chauvet, 1993; Lau et al., 2006; Mille-Lindblom et al., 2004; Pasanen et al., 1999). Ergosterol detection is typically performed by gas chromatography-mass spectrometry (GC-MS) (Burshtein et al., 2011; Lau et al., 2006), or high pressure liquid phase chromatography (HPLC) (Robine et al., 2005) and is reported as ergosterol mass per volume of air, or by using a conversion factor, as ergosterol mass per spore.

In order to determine if ergosterol content is consistently associated with the concentration of fungal spores, previous investigators have compared fungal concentrations based on culture enumeration with ergosterol mass concentration (Lau et al., 2006; Heid et al., 1996). However, spore counts based on culturability may not accurately reflect the true fungal content since nonviable species cannot be cultured, nor can fungal spores that require a different media or growth condition than provided in the culture assay. This limitation to culturing of environmental bacteria and fungi is well documented (Amann et al., 1995). In the case of airborne fungal spores, differences between total, intact spores and culturable counts as high as ten times have been documented (Hospodsky et al., 2010). In addition, sampling fungi onto agar plates is limited by desiccation and can only be performed for short (ca. $\sim 15 \mathrm{~min}$ ) sampling durations (Buttner et al., 1997).

Real-Time q-PCR analysis is based on direct detection of DNA extracted from sampled fungal spores and thus circumvents culturability limitations (Peccia and Hernandez, 2006; Alkan et al., 2004). In addition, bypassing the need for viable propagules enables sample collection onto filters and for longer periods of time, thus improving comparability by allowing fungal spore analysis to be performed on the same aerosol sample that is used for ergosterol.

In this study we analyzed the concentration of outdoor airborne fungal spores sampled throughout one year in Rehovot, Israel. We investigated the seasonal distribution of selected allergenic fungi species as indicators for the fungal community distribution, and compared total fungal concentrations (universal fungal qPCR primers) with ergosterol reported concentrations (Burshtein et al., 2011). Enumer- ation of airborne fungi by quantitative PCR is rapidly becoming the dominant method for exposure analysis in environmental and public health studies (Sacchi et al., 2011; Haugland, 2002 Zhou et al., 2000; Mackay, 2007). It is important that these values be compared with other commonly used biomarker assays to ensure that these measures provide similar assessments of relative exposure.

\section{Materials and methods}

\subsection{Sampling and storage}

Airborne particles were collected using a high volume sampler (Ecotech High volume sampler model ECO-HVS3000 with $\mathrm{PM}_{10}$ inlet) maintaining a constant flow rate of $67.8 \mathrm{~m}^{3} \mathrm{~h}^{-1}$. Forty-eight samples were collected over a period of one year (December 2008-December 2009), on the rooftop of a four story building in Rehovot, Israel (31_540200 N, 34_4803300 5 E). All sampling periods were $72 \mathrm{hr}$, except for two cases (23 August 2009 and 22 September 2009) where the sampling period was $24 \mathrm{~h}$. Sampled aerosols were collected on thermally pretreated $\left(450^{\circ} \mathrm{C}\right)$ quartz fiber filters $(20.3 \mathrm{~cm} \times 25.4 \mathrm{~cm}$ Whatman $)$. Immediately after sampling, filters were wrapped in aluminum foil and kept at $-20^{\circ} \mathrm{C}$ until the sampling campaign was completed. Subsequently, all samples were archived at $-80^{\circ} \mathrm{C}$ until analysis. The filter samples were segregated according to seasons as follows: Winter (December-February), Spring (March-May), Summer (June-August), Fall (SeptemberNovember).

\subsection{Universal and allergenic fungal spore identification and quantification by qPCR analysis}

Quantitative PCR was performed in accordance with previously described standard fungal DNA preparation protocols, DNA extraction methods, and quality control measures (Haugland, 2002; Yamamoto et al., 2011; Hospodsky et al., 2010). Briefly, DNA was extracted directly from three different $3 \mathrm{~cm} \times 3 \mathrm{~cm}$ subsamples filters for total fungi and $1 \mathrm{~cm} \times 3 \mathrm{~cm}$ for specific species, using the PowerSoil DNA Isolation Kit (MO BIO Laboratories Inc.) according to the manufacturers protocol, with modifications for high yields, as previously described in detail for fungi collected on glass fiber filters (Hospodsky et al., 2010).

Quantitative PCR analyses for total fungi sampled (i.e. universal fungi) were performed with a Step One Plus RealTime PCR (Applied Biosystems), using the FF2/FR1 assay (Table 1) (Zhou et al., 2000). A $10 \mu \mathrm{l}$ reaction mixture consisted of $5 \mu$ l Fast SYBR Green Master Mix (Applied Biosystems), $1 \mu \mathrm{l}$ extracted DNA, $0.5 \mu \mathrm{l}$ of each primer $(0.5 \mu \mathrm{M})$, and $3 \mu \mathrm{l}$ nuclease free water (NFW). The thermal cycling conditions consisted of an initial $20 \mathrm{~s}$ denaturation and enzyme activation at $95^{\circ} \mathrm{C}$, followed by 45 cycles of $3 \mathrm{~s}$ denaturation at $95^{\circ} \mathrm{C}$, and $30 \mathrm{~s}$ annealing and extension at $60^{\circ} \mathrm{C}$. 
Table 1. The qPCR assays as detailed in Zhou et al. (2000) and Haugland (2002).

\begin{tabular}{|c|c|c|}
\hline Assay name & Target fungal species & Primers and probes sequence $5^{\prime}-3^{\prime}$ \\
\hline FF2/FR1 & Universal fungi & $\begin{array}{l}\text { F: GGTTCTATTTTGTTGGTTTCTA } \\
\text { R: CTCTCAATCTGTCAATCCTTATT }\end{array}$ \\
\hline Aaltr & Alternaria alternata & $\begin{array}{l}\text { F: GGCGGGCTGGAACCTC } \\
\text { R: GCAATTACAAAAGGTTTATGTTTGTCGTA } \\
\text { P: TTACAGCCTTGCTGAATTATTCACCCTTGTCTTT }\end{array}$ \\
\hline Afumi & Aspergillus fumigatus, Neosartorya fischeri & $\begin{array}{l}\text { F: GCCCGCCGTTTCGAC } \\
\text { R: CCGTTGTTGAAAGTTTTAACTGATTAC } \\
\text { P: CCCGCCGAAGACCCCAACATG }\end{array}$ \\
\hline Cclad2 & Cladosporium cladosporioides, svar. 2 & $\begin{array}{l}\text { F: TACAAGTGACCCCGGCTACG } \\
\text { R: CCCCGGAGGCAACAGAG } \\
\text { P: CCGGGATGTTCATAACCCTTTGTTGTCC }\end{array}$ \\
\hline Enigr & Epicoccum nigrum & $\begin{array}{l}\text { F: TTGTAGACTTCGGTCTGCTACCTCTT } \\
\text { R: TGCAACTGCAAAGGGTTTGAAT } \\
\text { P: CATGTCTTTTGAGTACCTTCGTTTCCTCGGC }\end{array}$ \\
\hline PenGrp3 & $\begin{array}{l}\text { Penicillium chrysogenum/griseofulvum/ } \\
\text { glandicola/coprophilum/ } \\
\text { expansum and Eupenicillium }\end{array}$ & $\begin{array}{l}\text { F: CGGGCCCGCCTTAAC } \\
\text { R: GAAAGTTTTAAATAATTTATATTTTCACTCAGAGTA } \\
\text { P: CGCGCCCGCCGAAGACA }\end{array}$ \\
\hline PenAsp1mgb & $\begin{array}{l}\text { Universal Penicillium, Aspergillus and Pae- } \\
\text { cilomyces varioti }\end{array}$ & $\begin{array}{l}\text { F: CGGAAGGATCATTACTGAGTG } \\
\text { R: GCCCGCCGAAGCAAC } \\
\text { P: CCAACCTCCCACCCGTG }\end{array}$ \\
\hline
\end{tabular}

F: Forward primer; R: Reverse primer; P: Probe.

Cycle thresholds were calculated using the auto function in Step One Plus. Negative controls, with NFW, were run on each qPCR 96-well plate, and all q-PCR measurements of each filter were replicated at least three times. Standard curves based on known quantities of Aspergillus fumigatus fungal spores versus cycle threshold values were established for each q-PCR 96-well plate analyzed. Results for universal primers are reported as Aspergillus fumigatus (ATCC 34506) equivalent fungal spores.

For 25 representative sample filters, five medically important groups of allergenic fungi (Aspergillus fumigatus, Alternaria alternata, Cladosporium cladosporioides, Epicoccum nigrum, Penicillium spp. and the Penicillium/Aspergillus group) were chosen to be specifically analyzed (Table 1). In addition, a second set of biological replicates for universal fungi was repeated. DNA was extracted from filter samples as described above and real-time qPCR was performed. Specific allergens were quantified using the TaqMan method and employed the Afumi, Aaltr, Cclad2, Enigr, PenGrp3 and PenAsp1mgb assays (Table 1) reported by the US EPA (Haugland, 2002), and universal fungi detection was performed with the SYBR green method (FastStart Universal SYBR Green Master (ROX); Roche Applied Science), using the same assay as described above (Table 1). A $25 \mu$ reaction mixture containing the template DNA $(1 \mu \mathrm{l}$ sample extract), $1 \times$ TaqMan Universal PCR Master Mix (Applied Biosystems) for specific species or $12.5 \mu \mathrm{l}$ of FastStart Universal SYBR Green Master (Roche Applied Science) for universal fungi, $1 \mu \mathrm{M}$ of each primer, and $0.08 \mu \mathrm{M}$ of the probe for the specific species assays. A real-time PCR system (ABI 7500 Fast Real-time PCR System; Applied Biosystems) was used with the following cycle conditions: $50^{\circ} \mathrm{C}$ for $2 \mathrm{~min}, 95^{\circ} \mathrm{C}$ for $15 \mathrm{~min}$ of initial denaturation and 45 cycles at $95^{\circ} \mathrm{C}$ for $15 \mathrm{~s}$ dissociation and $60^{\circ} \mathrm{C}$ for $1 \mathrm{~min}$ of annealing and extension. All allergenspecific qPCR measurements were performed in triplicate. Standard concentrations of genomic DNA for the five specific allergenic fungi were prepared (i.e. Aspergillus fumigatus (ATCC 34506), Alternaria alternata (PEM 01043), Cladosporium cladosporioides (ATCC 16022), Epicoccum nigrum (PEM 01043), Penicillium chrysogenum (CAES PC1)) and standard qPCR curves were based on spore concentration versus cycle threshold values. PenAsp1mgb standard curves (amplification of both Penicillium and Aspergillus species) were generated using the A. fumigatus (ATCC 34506) DNA standard.

To test for PCR inhibition, seven randomly selected extracts from the filter samples were added to subsets of diluted E. nigrum DNA, and standard curves were produced. No significant inhibition was observed in this study. Accuracy, 
Table 2. Seasonally averaged values of fungal species concentrations, analyzed by qPCR*.

\begin{tabular}{lcccccc}
\hline Season & $\begin{array}{c}\text { A. alternata } \\
\text { (Aalt) }\end{array}$ & $\begin{array}{c}\text { A. fumigatus } \\
\text { (Afumi) }\end{array}$ & $\begin{array}{c}\text { C. cladosporidis } \\
\text { (Cclad2) }\end{array}$ & $\begin{array}{c}\text { E. nigrum } \\
\text { (Enigr) }\end{array}$ & $\begin{array}{c}\text { P. chrysogenum } \\
\text { (PenGrp3) }\end{array}$ & $\begin{array}{c}\text { Other** } \\
\text { (PenAsp1mgb) }\end{array}$ \\
\hline Winter & $189.62 \pm 1.1$ & $33.94 \pm 0.2$ & $181.79 \pm 4.4$ & $38.97 \pm 0.8$ & $42.75 \pm 3.1$ & $60.17 \pm 3.3$ \\
Spring & $117.69 \pm 2.7$ & $15.51 \pm 0.3$ & $81.85 \pm 2.7$ & $75.16 \pm 6.0$ & $13.64 \pm 0.3$ & $48.49 \pm 1.2$ \\
Summer & $320.92 \pm 1.7$ & $47.83 \pm 0.2$ & $256.43 \pm 6.0$ & $90.23 \pm 1.7$ & $33.34 \pm 0.5$ & $135.91 \pm 5.8$ \\
Fall & $1504.45 \pm 6.4$ & $264.88 \pm 0.5$ & $1657.66 \pm 56.8$ & $340.34 \pm 2.9$ & $168.23 \pm 1.8$ & $419.41 \pm 24.2$ \\
\hline
\end{tabular}

* Standard deviations are reported as average values. ** Other Penicillium and Aspergillus species, as detailed in Table 1.

precision, and method limit of detections where tested for these specific assays, and reported in Yamamoto et al. (2011).

\subsection{Ergosterol analysis}

Ergosterol extraction from the sample filters used in this study was previously reported (Burshtein et al., 2011). In short, the analysis was performed on each of the 48 filters in triplicates. $3 \mathrm{~cm} \times 3 \mathrm{~cm}$ sampled filter pieces were hydrolyzed to release the ergosterol into methanol solution. Ergosterol was extracted using phase separation of deionized water and hexane, and an internal standard of 7Dehydro cholesterol was added to each sample. Analysis was performed using GC-MS/MS (Varian GC-MS Saturn 2000 equipped with a Restek column).

\subsection{Quality control}

Quantitative-PCR analyses of the sampled filters were tested for their accuracy, precision, and method detection limits (MDL) as described in Hospodsky et al. (2010) and Yamamoto et al. (2011). Briefly, accuracy was determined by efficiencies in DNA extraction from sampling filters, and $10 \%$ of DNA extraction efficiency was used for fungal cells collected on quartz fiber filters (Hospodsky et al., 2010). Precision was defined as instrument repeatability as coefficients of variations (COVs) based on triplicate measurements for the study samples by qPCR. The qPCR MDL was defined as the smallest fungal concentration where seven successful PCR amplifications out of seven trials $(p=1 / 128)$ could be observed to detect a microorganism concentration with $99 \%$ confidence (Yamamoto et al., 2011). These values were converted into corresponding MDLs in air concentration $\left(\right.$ cell $\left.\mathrm{m}^{-3}\right)$ with information of the DNA extraction efficiency $(=10 \%)$ and the collected air volume, i.e. $4881.6 \mathrm{~m}^{3}$ (72-h sampling with $67.8 \mathrm{~m}^{3} \mathrm{~h}^{-1}$ ).

\subsection{Data analysis}

Correlations between ergosterol mass concentration and equivalent fungal spore concentrations were analyzed by Pearson correlation test. Variance between fungal species distributions was analyzed by One-way ANOVA between groups. Analysis of significant differences between seasons was done by One-way ANOVA followed by Tukey SHD post-hoc test for each allergenic assay.

\section{Results}

For quality control analyses performed to each of the genomic assays, precision was defined as instrument repeatability based on triplicate qPCR measurements for the study air samples. Median values of instrument repeatability as COVs were $59 \%, 19 \%, 31 \%, 21 \%, 33 \%, 34 \%$, and $13 \%$ for FF2/FR1, Aaltr, Afumi, Cclad2, Enigr, PenGrp3, and PenAsp1mgb, respectively. The qPCR MDLs for FF2/FR1, Aaltr, Afumi, Cclad2, Enigr, PenGrp3, and PenAsp1mgb assays were $0.05,0.28,0.05,0.07,0.07,2.8$, and 0.05 cells per reaction, respectively (Yamamoto et al., 2011). Accounting for the DNA extraction efficiency from fungal cells of $10 \%$ (Hospodsky et al., 2010) a sampling volume of $4881.6 \mathrm{~m}^{3}$ (72-h sampling with $67.8 \mathrm{~m}^{3} \mathrm{~h}^{-1}$ ), and fractions of the DNA extracts and the filter area used for the qPCR analysis, the overall MDLs in air concentration were 8.6, 4.9, 0.9, 1.2, 1.2, 49.3, and 0.9 cell $\mathrm{m}^{-3}$ for FF2/FR1, Aaltr, Afumi, Cclad2, Enigr, PenGrp3, and PenAsp1mgb, respectively.

We followed the seasonal distribution of selected allergyinducing fungal species (Fig. 1, Table 2). We found that A. alternata is the most abundant species out of all allergenproducing fungi tested, detected in three out of the four seasons (winter $-35 \%$, spring $-34 \%$, summer $-36 \%$ ), whereas in the fall, $C$. cladosporioides was the most prevalent $(38 \%)$ species. In the spring, a relatively high abundance of $E$. nigrum was detected (21\% compared to $7 \%, 10 \%$ and $8 \%$ in winter, summer and fall respectively). A. fumigatus, P. chrysogenum and other groups of Aspergillus and Penicillium were relatively scarcer and observed throughout all seasons with a similar ratio. ANOVA test between groups confirmed the null hypothesis for significant similarity between the species seasonal distributions (F-value $=0.03$, pvalue $=1.00$ ).

Figure 2 represents the values of both ergosterol (top graph) in $\mathrm{ng} \mathrm{m}^{-3}$ air, and total fungi (bottom graph) in equivalent spore $\mathrm{m}^{-3}$. The two biological replicates using universal fungi primers for the q-PCR experiments are 


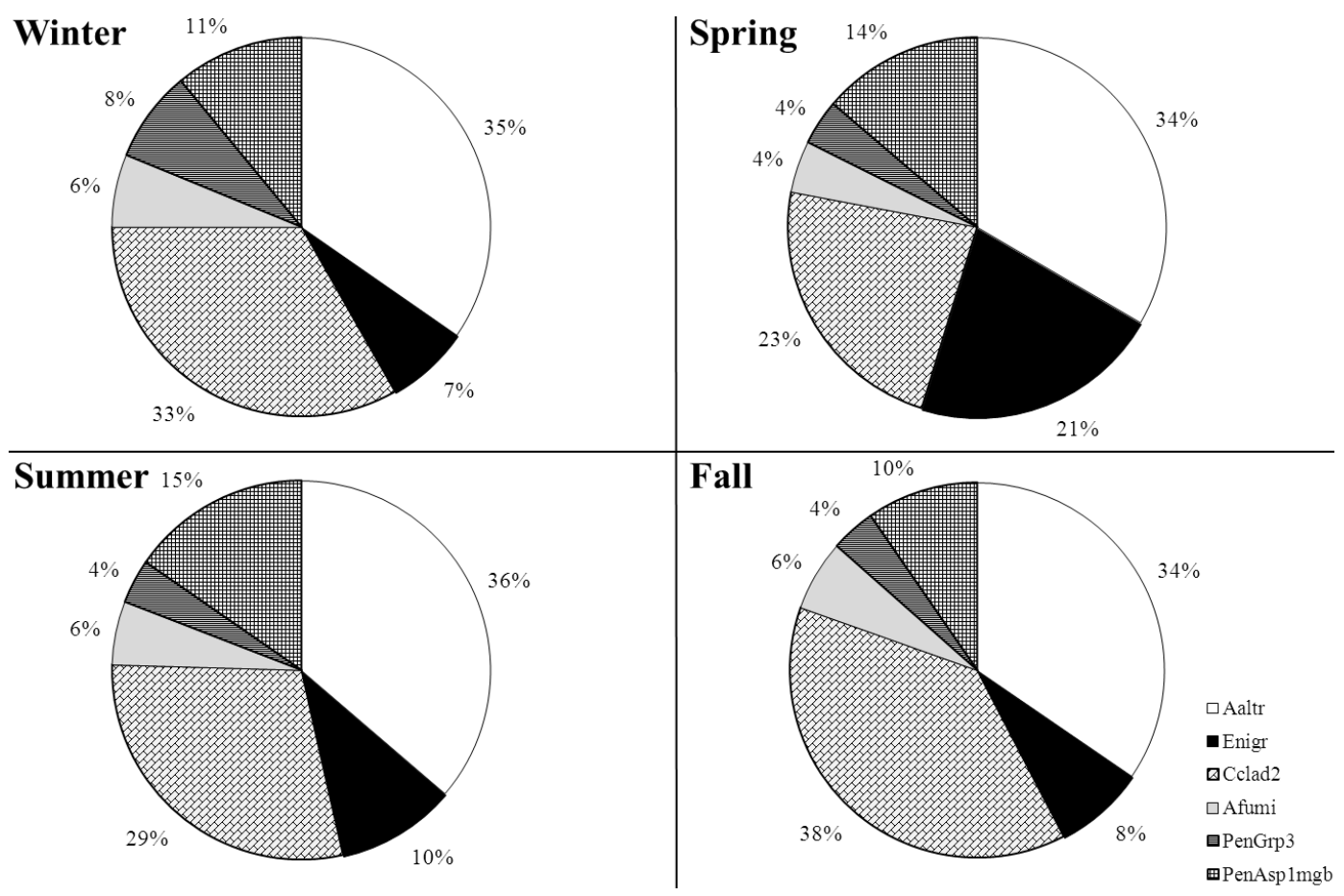

Fig. 1. Seasonal distributions of specific fungi species detected in sampled filters by q-PCR analysis (represented by the specific detection assays). The values represent the relative abundance out of the sum of the specific fungi considered.
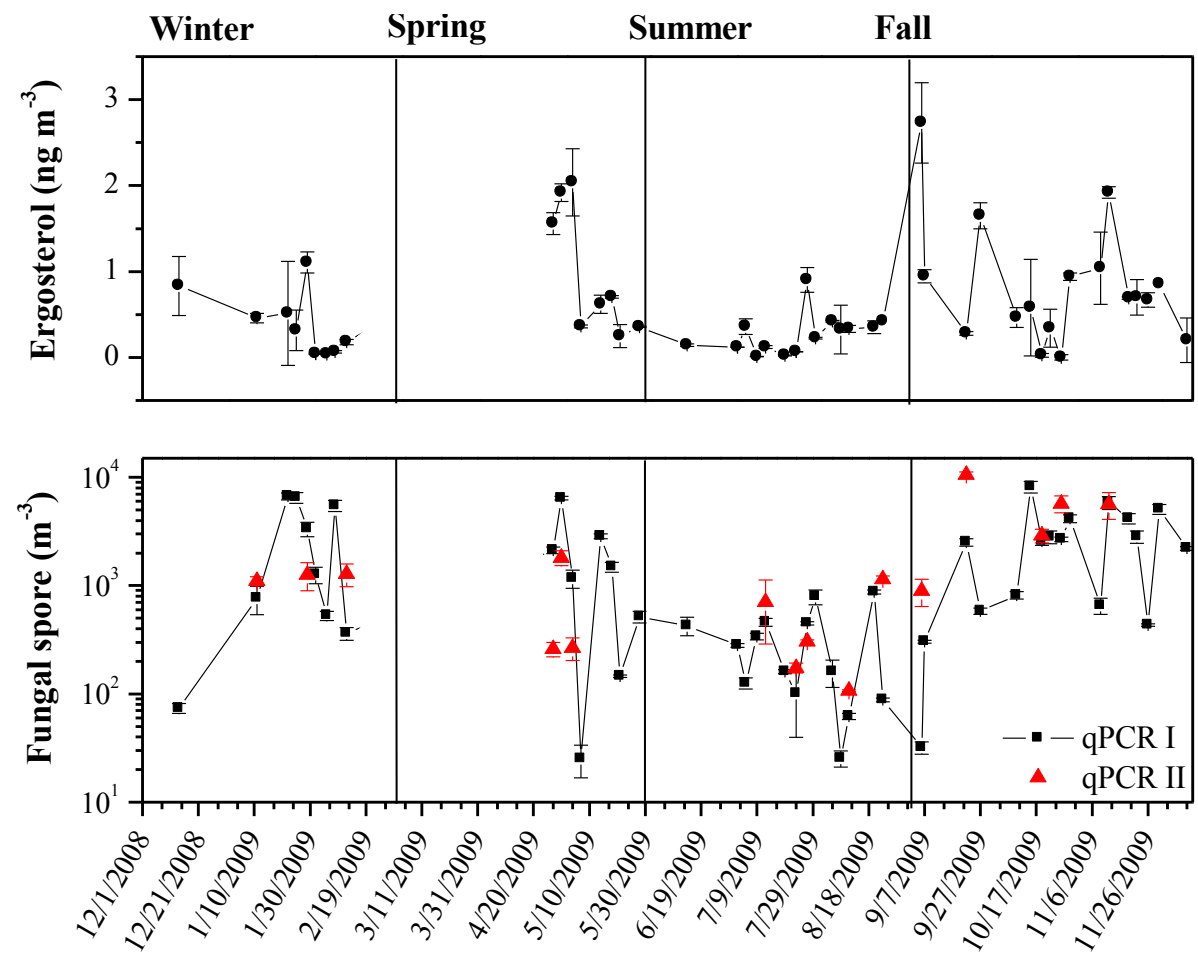

Fig. 2. Seasonal ergosterol concentrations (upper graph) (Burshtein et al., 2011), and fungal spore concentrations (bottom graph) from $\mathrm{PM}_{10}$ filters. The qPCR I and qPCR II values refer to independent sample repeats. The error bars are standard deviations, $n=48$ for ergosterol and qPCR I analysis of fungal spore, and $n=24$ for qPCR II analysis of fungal spore. 


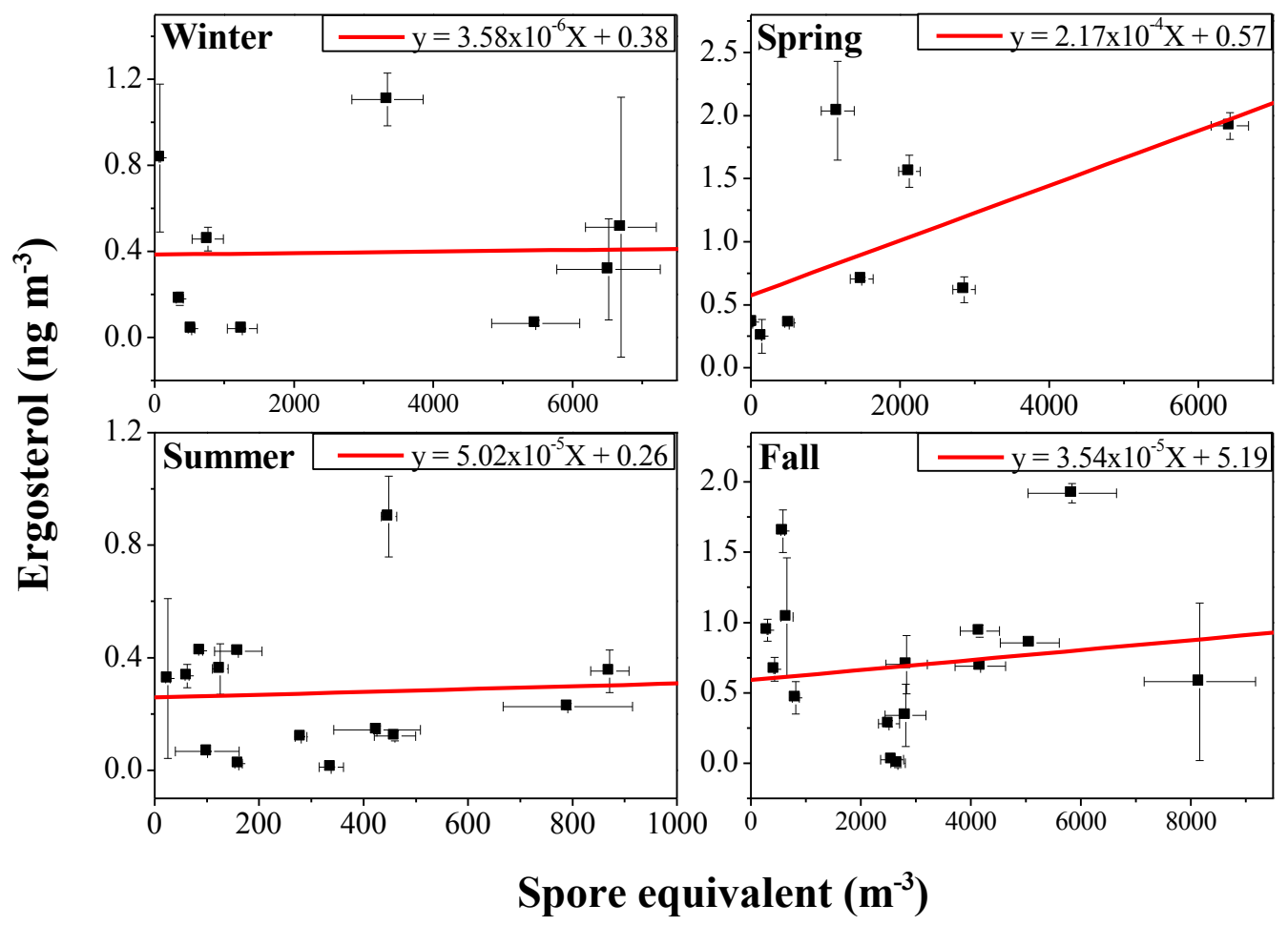

Fig. 3. Seasonal correlation between equivalent total fungal spore concentrations analyzed from q-PCR measurements, and ergosterol mass concentrations (Burshtein et al., 2011). The error bars represent the standard deviation of ergosterol (vertical) and fungi spore sampling replicates (horizontal).

represented by "qPCR I" and "qPCR II" respectively, where the "qPCR II" analyses were done for a seasonally representative part of the filters. The two repeated fungal spore concentrations are statistically similar (tested by independent two sample t-test, $p$-value $=0.713$ ). Both fungal spore and ergosterol concentrations indicate that fungal mean concentrations are lowest in the summer period $(356.6 \pm 265.7,0.28 \pm 0.23$, respectively) and highest in the fall $(2896.9 \pm 2240.1,0.94 \pm 0.71$, respectively, see Table 3). A local maximum in the spring (between 14 and 18 May) also shows similarity between the two parameters. As can be seen, the inter-season and intra-season variability can span 1-2 orders of magnitude in concentration. No clear trend can be identified in our data. By averaging samples across individual seasons, the ranking of fungal spore concentrations is fall $>$ winter $>$ spring $>$ summer. The seasonal ranking scheme of ergosterol concentrations is fall $>$ spring $>$ winter $>$ summer. It is therefore important to understand the sources of these inconsistencies.

We tried to correlate ergosterol and fungal spore concentrations linearly, as detailed in Table 3 and Fig. 3. We did not find a yearly correlation between the two parameters $(r=0.18 \pm 0.61, \mathrm{p}$-value $=0.21)$. When correlating seasonally, a positive correlation was observed only in the spring $(r=0.61 \pm 0.63, \mathrm{p}$-value $=0.1$, double asterisk in Table 3$)$. A semi-log correlation was performed as well, since spore concentration analyzed from qPCR data are log-normally distributed (Maher, 1981; di Giorgio et al., 1996), however no improved correlation was detected.

In order to eliminate possible errors in qPCR analysis that may arise from genome to total spore conversion, we further examined the prevalence of specific fungal species by utilizing qPCR analysis with species-specific assays (Table 1). Assuming that these species comprise a good representation of the total sampled fungal spores, we summed the analyzed species and compared this sum to the ergosterol concentrations (Fig. 4). Similarly to both ergosterol and qPCR analyses for equivalent spore concentration, a higher spore concentration of all species was detected in the fall, with the exception of E. nigrum, which had the highest values in the spring season (70.04 at spring compared to 62.45 spores $\mathrm{m}^{-3}$ at fall). However, only a weak yearly correlation was found between ergosterol and the sum of specific fungal spore concentrations $(r=0.35 \pm 0.96$; $\mathrm{p}$-value $=0.13)$. Seasonal correlations could not be calculated due to the low number of samples per season. 

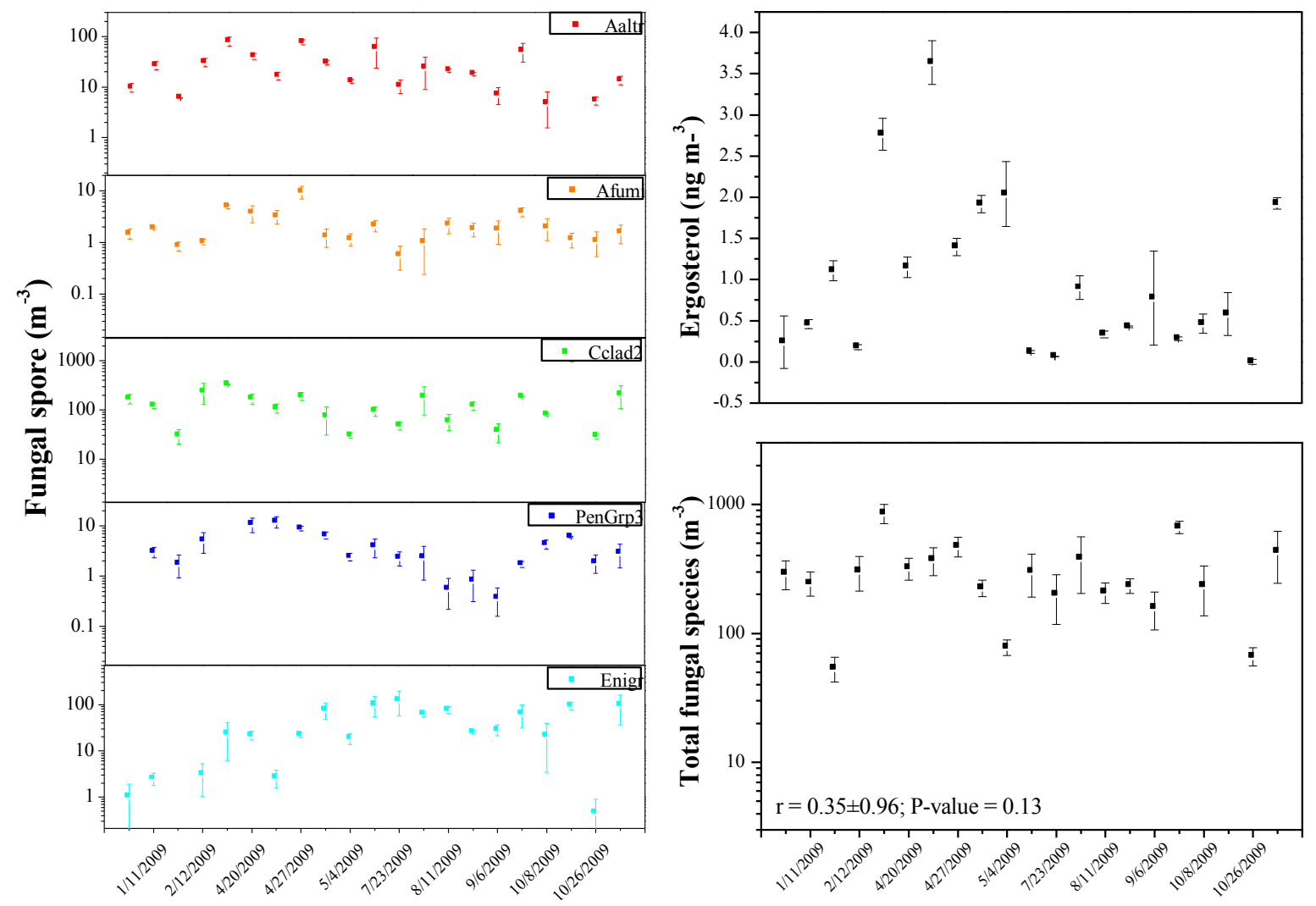

Fig. 4. Seasonal ergosterol concentrations (top right graph) (Burshtein et al., 2011), compared to the sum of specific fungal spore concentrations (bottom right graph) from $\mathrm{PM}_{10}$ filters, with a correlation coefficient specified in the lower graph. The specific fungal species are specified on the left graphs (Alternaria alternata, Aaltr; Aspergillus fumigatus, Afumi; Cladosporium cladosporioides, Cclad2; Penicillum Chrysogenum, PenGrp3 Eppicocum nigrum, Enigr). The error bars are standard deviations, $\mathrm{n}=21$ samples for ergosterol, and $n=25$ samples for fungal spore.

Table 3. Seasonal correlation coefficients between Ergosterol and spore concentrations*.

\begin{tabular}{lcccc}
\hline Season & Ergosterol $\mathrm{ng} \mathrm{m}^{-3}$ & Spore $^{-3}$ & Correlation coefficient, $r$ & p-value \\
\hline Winter & $0.42 \pm 0.4$ & $2044.6 \pm 2772$ & $0.03 \pm 0.40$ & 0.95 \\
Spring & $0.76 \pm 0.7$ & $1380.6 \pm 2090$ & $0.61 \pm 0.63^{* *}$ & 0.10 \\
Summer & $0.28 \pm 0.2$ & $356.6 \pm 266$ & $0.06 \pm 0.24$ & 0.84 \\
Fall & $0.94 \pm 0.7$ & $2896.9 \pm 2240$ & $-0.15 \pm 0.72$ & 0.55 \\
Whole year & $0.61 \pm 0.6$ & $1873.8 \pm 2195$ & $0.18 \pm 0.61$ & 0.21 \\
\hline
\end{tabular}

* Ergosterol and spore values are presented by the season mean value, as well as the standard deviations.

* Statistically significant.

\section{Discussion}

The ability to quantify fungal spores concentration and species in atmospheric particulate matter is necessary for reducing or preventing exposure to infectious plant and human fungal agents and to fungal allergens (Madelin, 1994). Here we used DNA analysis to study the spore annual distribution of 5 allergy-causing fungal species in the Eastern Mediterranean. In addition, we conducted a comparative analysis of the airborne fungal spores and ergosterol concentrations and attempted to correlate the quality and reliability of conventional biomarker analyses to the emerging methods based on DNA sequence analysis.

In quality control analysis (Hospodsky et al., 2010; Yamamoto et al., 2011) we ensured that our genomic measurements were accurate due to both the correction performed for the DNA extraction efficiency $(10 \%)$, and the lack of PCR inhibition in our samples. The precision of the measurements 
was ensured by performing technical triplicates for each of the reactions in the qPCR analysis. While field replicates would enable the definition of the overall measurement precision (including variations associated with air sampling and DNA extraction) (Yamamoto et al., 2011), the variations associated with DNA extraction and air sampling are typically much smaller than those associated with qPCR. Therefore, the qPCR COVs are likely to be good approximations for the overall measurement COVs, including air sampling, DNA extraction, and qPCR. PenGrp3 was the only qPCR assay where many of the sample values were less than the MDL. This is probably due to the relatively low PCR efficiency compared to the other assays. Because this fungal group is scarce, the impact on the overall species distribution in each season is minimal.

Even though the major source of incoming air at the sampling location changes considerably in the different seasons, the fungal species distribution did not change significantly throughout the year (Burshtein et al., 2011; Dayan and Levy, 2005; Erel et al., 2006). This phenomenon of similar species' seasonal distributions might be attributed to local fungal sources, which did not experience extreme seasonal changes in the local climate in Israel, buffered by the Mediterranean Sea. In our previous published work (Burshtein et al., 2011) we calculated back trajectories to the sample filters and found the highest ergosterol levels when back trajectories showed local terrestrial origin. Therefore, qualitatively we must conclude that the majority of the fungal spores most likely come from local origin. The only significant change in spore concentration was observed in the spring for E. nigrum. It might be that apart from the local source, this elevated value is attributed to additional sources. Further analysis is needed in order to understand the origin of different fungal species. For example, source apportionment analysis, or parallel sampling in a different climatic region in the same area (such as the Negev desert in the south of Israel, or a rural mediterranean forest in the northern Galilee) may lead to a better understanding of the species origin. The observed species' distributions are most important with respect to plant diseases and human allergies; however we cannot deduce their potency from this data, or their actual ability to induce allergies. Further investigation on the allergenic effects and potency is needed in order to clarify this point.

Ergosterol is considered a reliable proxy for fungal spore concentrations (Lau et al., 2006; Burshtein et al., 2011; Mille-Lindblom et al., 2004; Miller et al., 1997). We compared ergosterol concentrations with DNA-based analyses of airborne $\mathrm{PM}_{10}$ fraction of fungal spores to test this notion. Although DNA-based analysis of environmental fungal content is now becoming routine, comparisons with chemical biomarker analysis have not been undertaken. Positive correlation was found between DNA-based analysis and ergosterol concentrations only in the spring season, with p-value higher, but close to the null limit of rejection, $a$. Hence the observed correlation is weakened accordingly. Throughout the entire year, correlation for total fungi concentrations was not found. Ergosterol correlation to the sum of specific fungal species was found to be weak, with a low p-value.

The lack of correlations between ergosterol and equivalent fungal spore concentrations may be associated with the influence of sampling conditions, as well as environmental factors on fungal growth and physiology, which lead to changes in ergosterol production, as investigated previously (Bjurman, 1994; West et al., 1987; Li et al., 2009; Nout et al., 1987). For example, as was shown by Li et al. (2009), changes in growth temperature lead to changes in ergosterol content in Penicillium roqueforti, with an optimum content at $20^{\circ} \mathrm{C}(\mathrm{Li}$ et al., 2009).

Ergosterol degradation induced by potential environmental factors such as UV light, ozone, $\mathrm{NO}_{\mathrm{x}}$, high $\mathrm{RH}$ etc. may contribute to the observed differences as well. In general, using biomarkers for the determination of an organism's concentrations holds an inherent uncertainty due to these factors, which could induce its degradation. DNA analyses (e.g. qPCR), on the other hand, would not be influenced by either growth conditions or environmental factors, and would reflect the true sampled fungi content.

Ergosterol mass concentration is often reported in equivalent spore concentrations (Pasanen et al., 1999; Lau et al., 2006) and references therein. This conversion, based on the assumption that ergosterol represents viable spores (MilleLindblom et al., 2004), is calculated by comparing the parallel sampling of filters and viable sampling on agar plates. The enumerated viable fungal spores are correlated to the ergosterol mass concentration analyzed from the filters and a conversion factor is then determined. This conversion introduces errors into the reported data from both the different sampling time scale and the presence of non-viable or uncultivable spores that are not included in the viable measurement (Amann et al., 1995). Hence the uncertainty about the consistency of the conversion factor cannot be ignored.

DNA analysis is more reliable with respect to its molecular stability compared to ergosterol measurements. Although DNA molecules might degrade as well due to cell damage during spore transport through the air, the rates are expected to be low for spore genomes (Després et al., 2007; FröhlichNowoisky et al., 2009; Griffin, 2004; Griffin and Kellogg, 2004). Therefore, for atmospheric samples DNA-based analyses might be preferable in order to detect and quantify the presence of fungal spores rather than biomarker molecules.

Fungal genome to spore conversion based on specific unicellular conidia (as was done in this study) may incorporate errors as well, as some fungal spores are multi-cellular, multi-nuclear, or both (Smith et al., 1975; Cummins et al., 2003). In addition, the genomes of fungal cells contain multiple copies of the target rRNA encoding genes, and the number of copies may vary substantially between different species of fungi (DePriest and Been, 1992; van Belkum et al., 1998; Gargas and DePriest, 1996). Thus, while species level qPCR results can be reliably converted back to the number of 
genomes and ultimately whole cell concentrations, accurate whole cell concentrations cannot be derived when using universal qPCR primers due to the unknown mixture of species that are included in the universal qPCR assay. Amplifying segments of single copy genes (while also avoiding genes that belong to gene families) may be a good solution for calibrating DNA (Amnuaykanjanasin and Epstein, 2003). A possible drawback in this approach is the reduction in sensitivity due to the low detection levels, especially when studying environmental samples, since there is only one gene copy per cell. In addition, variations in the number of nuclei per conidia, common in fungi, as well as the fact that some fungi (e.g. A. alternata) produce condia with several cells, will induce errors in this case as well. Further investigation of universal fungi is needed in order to properly quantify them in cases of environments with varying fungal distributions. Variations such as gene copy per genome or cell are typically inherent to the fungal species and are not dependent on growth conditions; therefore if the fungal population does not change from sample to sample, qPCR with universal primers should provide a consistent, relative measure of fungal spore content. In this study, the even distribution of species throughout the year (Fig. 1) suggests that the gene copy variations above did not contribute to the variability in the reported qPCR data. While this will not be the case for all environmental fungal samples, the consistent diversity throughout the year allows for the qPCR values here to be a consistent representation of spore content. Therefore, we suggest that ergosterol variations detected between samples may be attributed to deviations per spore. These deviations are most likely caused by changes in fungal growth conditions in addition to different degradation rates of ergosterol and the fungal genome in the atmosphere and on the filter.

\section{Summary}

By analyzing airborne fungal spore concentration over a period of one year, we found that the variation between species is small in the studied region. A lack in correlation between ergosterol mass concentrations and fungal spore concentrations was found from qPCR analyses. This is most likely due to ergosterol production rates fluctuating with changing growth conditions, in addition to its degradation during spore transport in the atmosphere. Even though this was a one year experiment, the fact that no correlation was observed is sufficient to conclude that there are severe drawbacks to ergosterol-based quantification. This finding should be taken into consideration when monitoring fungal spore concentrations.

Acknowledgements. This research was supported by a research grant from the Dr. Angel Faivovich foundation for Ecological Studies. N. Lang-Yona was supported by a grant from the Environmental Health Fund, K. Dannemiller was supported by a US National Science Foundation fellowship, and N. Yamamoto is supported by the Japan Society for the Promotion of Science. Y.R. acknowledges support by the Helen and Martin Kimmel Award for Innovative Investigation.

Edited by: R. MacKenzie

\section{References}

Alkan, N., Gadkar, V., Coburn, J., Yarden, O., and Kapulnik, Y.: Quantification of the Arbuscular Mycorrhizal Fungus Glomus intraradices in Host Tissue Using Real-Time Polymerase Chain Reaction, New Phytol., 161, 877-885 2004.

Amann, R. I., Ludwig, W., and Schleifer, K. H.: Phylogenetic identification and in situ detection of individual microbial cells without cultivation, Microbiol. Mol. Biol. Rev., 59, 143-169, 1995.

Amnuaykanjanasin, A. and Epstein, L.: A class V chitin synthase gene, chsA is essential for conidial and hyphal wall strength in the fungus Colletotrichum graminicola (Glomerella graminicola), Fungal Genet. Biol., 38, 272-285, 2003.

Axelsson, B.-O., Saraf, A., and Larsson, L.: Determination of ergosterol in organic dust by gas chromatography-mass spectrometry, J. Chromat. B: Biomed. Sci. Appl., 666, 77-84, 1995.

Bjurman, J.: Ergosterol as an indicator of mould growth on wood in relation to culture age, humidity stress and nutrient level, Int. Biodeter. Biodegr., 33, 355-368, 1994.

Breitenbach, M. C. R. and Lehrer, S. B.: Fungal allergy and pathogenicity, 08, edited by: Breitenbach, M. C. R. and Lehrer, S. B., Cambridge Journals Online, 310 pp., 2002.

Burshtein, N., Lang-Yona, N., and Rudich, Y.: Ergosterol, arabitol and mannitol as tracers for biogenic aerosols in the eastern Mediterranean, Atmos. Chem. Phys., 11, 829-839, doi:10.5194/acp-11-829-2011, 2011.

Buttner, M. P., Willeke, K., and Grinshpun, S. A.: Sampling and Analysis of Airborne Microorganisms, Manual of Environmental Microbiology, edited by: Hurst, C. J., ASM Press, Washington, D.C., 629-640 pp., 1997.

Cummins, G. B. and Hiratsuka, Y.: Illustrated Genera of Rust Fungi, 3rd Edition ed., American Phytopathological Society, St. Paul, Minnesota, USA, 223 pp., 2003.

Dayan, U. and, Levy, I.: The Influence of Meteorological Conditions and Atmospheric Circulation Types on $\mathrm{PM}_{10}$ and Visibility in Tel Aviv, J. Appl. Meteo., 44, 606-619, 2005.

DePriest, P. T. and Been, M. D.: Numerous group I introns with variable distributions in the ribosomal DNA of a lichen fungus., J. Mol. Biol., 228, 315-321, 1992.

Després, V. R., Nowoisky, J. F., Klose, M., Conrad, R., Andreae, M. O., and Pöschl, U.: Characterization of primary biogenic aerosol particles in urban, rural, and high-alpine air by DNA sequence and restriction fragment analysis of ribosomal RNA genes, Biogeosciences, 4, 1127-1141, doi:10.5194/bg-4-1127-2007, 2007.

di Giorgio, C., Krempff, A., Guiraud, H., Binder, P., Tiret, C., and Dumenil, G.: Atmospheric pollution by airborne microorganisms in the city of Marseilles, Atmos. Environ., 30, 155-160, 1996.

Enoch, D. A., Ludlam, H. A., and Brown, N. M.: Invasive fungal infections: a review of epidemiology and management options, J. Med. Microbiol., 55, 809-818, doi:10.1099/jmm.0.46548-0, 2006. 
Erel, Y., Dayan, U., Rabi, R., Rudich, Y., and Stein, M.: Trans Boundary Transport of Pollutants by Atmospheric Mineral Dust, Environ. Sci. Tech., 40, 2996-3005, doi:10.1021/es0515021, 2006.

Fröhlich-Nowoisky, J., Pickersgill, D. A., Després, V. R., and Pöschl, U.: High diversity of fungi in air particulate matter, Proc. Natl. Acad. Sci. USA, 106, 12814-12819, doi:10.1073/pnas.0811003106, 2009.

Gange, A. C., Gange, E. G., Sparks, T. H., and Boddy, L.: Rapid and Recent Changes in Fungal Fruiting Patterns, Science, 316, 71-71, doi:10.1126/science.1137489, 2007.

Gargas, A. and DePriest, P. T.: A nomenclature for fungal PCR primers with examples from intron-containing SSU rDNA, Mycologia, 88, 745-748 1996.

Garvey, G. and Keller, N.: Fungal Secondary Metabolites and Their Fundamental Roles in Human Mycoses, Curr. Fungal Infect. Rep., 4, 256-265, 2010.

Gessner, M. O. and Chauvet, E.: Ergosterol-to-Biomass Conversion Factors for Aquatic Hyphomycetes, Appl. Environ. Microbiol., 59, 502-507, 1993.

Griffin, D. W.: Terrestrial Microorganisms at an Altitude of $20000 \mathrm{~m}$ in Earth's Atmosphere, Aerobiologia, 20, 135-140, 2004.

Griffin, D. W. and Kellogg, C. A.: Dust Storms and Their Impact on Ocean and Human Health: Dust in Earth's Atmosphere, EcoHealth, 1, 284-295, 2004.

Haugland, R. a. V. S.: Method of identifying and quantifying specific fungi and bacteria., USA, U. S. E. P. A., 2002.

Heid, C. A., Stevens, J., Livak, K. J., and Williams, P. M.: Real time quantitative PCR, Genome Res., 6, 986-994, doi:10.1101/gr.6.10.986, 1996.

Hospodsky, D., Yamamoto, N., and Peccia, J.: Accuracy, Precision, and Method Detection Limits of Quantitative PCR for Airborne Bacteria and Fungi, Appl. Environ. Microbiol., 76, 7004-7012, doi:10.1128/aem.01240-10, 2010.

Kilronomos, J. N., Rillig, M. C., Allen, M. F., Zak, D. R., Pregitzer, K. S., and Kubiske, M. E.: Increased levels of airborne fungal spores in response to Populustremuloides grown under elevated atmospheric $\mathrm{CO}_{2}$, Can. J. Bot., 75, 1670-1673, 1997.

Kurup, V. P., Shen, H. D., and Banerjee, B.: Respiratory fungal allergy, Microbes Infect., 2, 1101-1110, 2000.

Lau, A. P. S., Lee, A. K. Y., Chan, C. K., Fang, M.: Ergosterol as a biomarker for the quantification of the fungal biomass in atmospheric aerosols, Atmos. Environ., 40, 249-259, 2006.

Li, Y., Wadsö, L., and Larsson, L.: Impact of temperature on growth and metabolic efficiency of Penicillium roqueforti - correlations between produced heat, ergosterol content and biomass, J. Appl. Microbiol., 106, 1494-1501, 2009.

Li, L., Lei, C., and Liu, Z. G.: Investigation of Airborne Fungi at Different Altitudes in Shenzhen University, Natural Science, 2, 506-514, 2010.

Mackay, I. M.: Real-Time PCR in Microbiology: From Diagnosis to Characterization., edited by: Mackay, I. M., Caister Academic Press, Queensland, Australia, 2007.

Madelin, T. M.: Fungal aerosols: A review, J. Aerosol Sci., 25, 1405-1412, 1994.
Maher, L. J.: Statistics for microfossil concentration measurements employing samples spiked with marker grains, Rev. Palaeobot. Palyno., 32, 153-191, 1981.

Mille-Lindblom, C., von Wachenfeldt, E., and Tranvik, L. J.: Ergosterol as a measure of living fungal biomass: persistence in environmental samples after fungal death, J. Microbiol. Methods, 59, 253-262, 2004.

Miller, J. D. and Young, J. C.: The Use of Ergosterol to Measure Exposure to Fungal Propagules in Indoor Air, Am. Ind. Hyg. Assoc. J., 58, 39-43, 1997.

Nout, M. J. R., Bonants-van Laarhoven, T. M. G., Jongh, P., and Koster, P. G.: Ergosterol content of Rhizopus oligosporus NRRL 5905 grown in liquid and solid substrates, Appl. Microbiol. Biot., 26, 456-461, 1987.

Oliveira, M., Ribeiro, H., and Abreul, I.: Annual Variation of Fungal Spores in Atmosphere of Porto: 2003, Ann. Agric. Environ. Med., 12, 309-315, 2005.

Pasanen, A.-L., Yli-Pietila, K., Pasanen, P., Kalliokoski, P., and Tarhanen, J.: Ergosterol Content in Various Fungal Species and Biocontaminated Building Materials, Appl. Environ. Microbiol., 65, 138-142, 1999.

Peccia, J. and Hernandez, M.: Incorporating polymerase chain reaction-based identification, population characterization, and quantification of microorganisms into aerosol science: A review, Atmos. Environ., 40, 3941-3961, doi:10.1016/j.atmosenv.2006.02.029, 2006.

Robine, E., Lacaze, I., Moularat, S., Ritoux, S., and Boissier, M.: Characterisation of exposure to airborne fungi: Measurement of ergosterol, J. Microbiol. Methods., 63, 185-192, 2005.

Sacchi, C. T., Fukasawa, L. O., Gonçalves, M. G., Salgado, M. M., Shutt, K. A., Carvalhanas, T. R., Ribeiro, A. F., Kemp, B., Gorla, M. C. O., Albernaz, R. K., Marques, E. G. L., Cruciano, A., Waldman, E. A., Brandileone, M. C. C., Harrison, L. H., and São Paulo, R. T. P. C. R. S. P. T.: Incorporation of Real-Time PCR into Routine Public Health Surveillance of Culture Negative Bacterial Meningitis in São Paulo, Brazil, PLoS ONE, 6, e20675, 2011.

Smith, J. E. and Berry, D. R. (Eds.): The filamentous fungi, vol. I. Industrial mycology, John Wiley \& Sons, New York, USA, 340 pp., 1975.

Takahashi, T.: Airborne Fungal Colony-Forming Units in Outdoor and Indoor Environments in Yokohama, Japan, Mycopathologia, 139, 23-33, 1997.

van Belkum, A., Scherer, S., van Alphen, L., and Verbrugh, H.: Short-Sequence DNA Repeats in Prokaryotic Genomes, Microbiol. Mol. Biol. Rev., 62, 275-293, 1998.

West, A. W., Grant, W. D., and Sparling, G. P.: Use of ergosterol, diaminopimelic acid and glucosamine contents of soils to monitor changes in microbial populations, Soil Biol. Biochem., 19, 607-612, 1987.

Yamamoto, N., Shendell, D. G., and Peccia, J.: Assessing allergenic fungi in house dust by floor wipe sampling and quantitative PCR., Indoor Air, 21, 521-530, 2011.

Zhou, G., Whong, W. Z., Ong, T., and Chen, B.: Development of a fungus-specific PCR assay for detecting low-level fungi in an indoor environment, Mol. Cell. Probe., 14, 339-348, 2000. 